\title{
Perbedaan Indeks Kebersihan Mulut dan Kualitas Hidup Terkait Kesehatan Rongga Mulut pada Pasien Diabetes Melitus Tipe 2 dan Non Diabetes Melitus
}

\author{
Farahdilla A. Putri, ${ }^{1}$ Setyo G. Pramudo, ${ }^{2}$ Ira A. Kusuma ${ }^{1}$, Avina A. Nasia, ${ }^{1}$
}

${ }^{1}$ Departemen Kedokteran Gigi Fakultas Kedokteran Universitas Diponegoro, Semarang, Jawa Tengah, Indonesia

${ }^{2}$ Bagian Ilmu Penyakit Dalam Fakultas Kedokteran Universitas Diponegoro, Semarang, Jawa Tengah, Indonesia

Email korespondensi: avina.anin@fk.undip.ac.id

\begin{abstract}
Type 2 diabetes mellitus (T2DM) is associated with many complications, one of them is oral health problem. Its risk increases in individual with poor oral hygiene. Oral health problem can impair daily life functions such as biting or chewing, speaking, and social interaction. However, research evidences investigating oral hygiene and quality of life related to oral health are still contradictory, therefore, further studies are still required. This study was aimed to evaluate the difference in oral hygine index and quality of life $(\mathrm{QoL})$ related to oral health index between T2DM and non DM patients. This was an observational study with a cross sectional design. Samples consisted of 21 T2DM patients and non DM patients at the Internal Medicine Outpatient Clinic of RSND hospital. Oral hygiene examination (OHI-S) was performed on all patients. Moreover, all patients had to fill the questionnaire which evaluated their QoL related to their oral health conditions (OHIP-14). Data were analyzed by using unpaired T-test and Mann-Whitney test. The results showed that the means of OHIS index were 3.17 in T2DM group and 1.43 in non DM group ( $<0.001$ ). Meanwhile the means of OHIP-14 index were 7.14 in T2DM group and 2.24 in non DM group $(\mathrm{p}<0.001)$. In conclusion, T2DM patients significantly have worse oral hygiene index and QoL related to oral health index than non DM patients.
\end{abstract}

Keywords: type 2 diabetes mellitus (T2DM), oral hygiene, quality of life related to oral health

\begin{abstract}
Abstrak: Diabetes melitus tipe 2 (DMT2) terkait dengan berbagai komplikasi, salah satunya masalah kesehatan rongga mulut yang risikonya semakin meningkat pada individu dengan kebersihan mulut yang buruk. Masalah kesehatan rongga mulut dapat membatasi fungsi seharihari seperti menggigit/mengunyah, berbicara, dan interaksi sosial. Namun, temuan beberapa penelitian mengenai kebersihan mulut dan kualitas hidup terkait kesehatan rongga mulut pada pasien DMT2 masih menunjukkan hasil yang bertentangan, sehingga diperlukan penelitian lebih lanjut. Penelitian ini bertujuan untuk mengetahui perbedaan indeks kebersihan mulut dan kualitas hidup terkait kesehatan rongga mulut pada pasien DMT2 dan non DM. Jenis penelitian ialah observasional dengan desain potong lintang. Sampel penelitian terdiri dari 21 pasien DMT2 dan 21 pasien non DM di Instalasi Rawat Jalan Penyakit Dalam RSND. Seluruh pasien menjalani pemeriksaan kebersihan mulut (OHI-S) dan juga diminta untuk mengisi kuesioner yang menilai kualitas hidup terkait kesehatan rongga mulut pasien (OHIP-14). Uji statistik menggunakan uji t tidak berpasangan. Hasil penelitian mendapatkan nilai rerata OHIS ialah 3,17 pada kelompok DMT2 dan 1,43 pada kelompok non DM ( $<<0,001)$. Nilai rerata OHIP-14 ialah 7,14 pada kelompok DMT2 dan 2,24 pada kelompok non DM ( $\mathrm{p}<0,001)$. Simpulan penelitian ini ialah pasien DMT2 memiliki skor indeks kebersihan mulut dan kualitas hidup terkait kesehatan rongga mulut yang lebih buruk secara bermakna dibandingkan pasien non DM.
\end{abstract}

Kata kunci: diabetes melitus tipe 2 (DMT2), kebersihan mulut, kualitas hidup terkait kesehatan rongga mulut 


\section{PENDAHULUAN}

Diabetes melitus tipe 2 (DMT2) ditandai dengan resistensi insulin yang telah berlangsung biasanya dalam durasi tahunan. Onset berawal dari hilangnya kemampuan sel beta merespon secara cepat terhadap kenaikan glukosa plasma. ${ }^{1}$ Jumlah individu dengan diabetes melitus meningkat dari 108 juta di tahun 1980 ke 422 juta orang pada 2014 di seluruh dunia. ${ }^{2}$ Di Indonesia sendiri terdapat sekitar 10.276.100 kasus diabetes pada tahun $2017 .^{3}$

Diabetes melitus terkait dengan berbagai komplikasi jangka panjang yang memberatkan penyandang DM. ${ }^{1}$ Terdapat lima komplikasi klasik yang berkaitan dengan diabetes yaitu retinopati, neuropati, nefropati, komplikasi kardiovaskular, dan luka yang sulit sembuh. Belakangan ini penyakit periodontal dianggap sebagai komplikasi ke enam dari DM. ${ }^{4}$ Manifestasi oral pada pasien dengan DM berupa penyakit periodontal, kandidiasis oral, gigi lepas, ulkus mukosa oral, gangguan indra perasa, xerostomia dan hipofungsi kelenjar saliva, karies dentis, dan sensasi terbakar pada mulut. ${ }^{5}$ Masalah kesehatan mulut tersebut dapat memengaruhi berbagai bidang termasuk penampilan, fungsi oral, dan hubungan interpersonal yang selanjutnya menyebabkan kualitas hidup yang lebih buruk. ${ }^{6,7}$

Beberapa penelitian telah menunjukkan bahwa pasien dengan DMT2 memiliki kebersihan mulut yang lebih buruk. Salah satunya ialah terkait pengetahuan kesehatan mulut yang inadekuat, sikap yang buruk terhadap kesehatan mulut, dan kunjungan ke dokter gigi yang lebih kurang. Namun hasil dari penelitian-penelitian tersebut saling bertentangan dan beberapa di antaranya melaporkan rerata indeks kebersihan mulut (OHI) yang sama pada pasien DM dan non DM. ${ }^{8,9}$

Beberapa penelitian menunjukkan gangguan oral dapat memengaruhi kualitas hidup, Namun efek gangguan tersebut pada pasien DM masih belum diteliti dengan baik dan menunjukkan hasil yang saling bertentangan. ${ }^{7,10,11}$ Banyak penelitian menunjukkan hubungan timbal balik antara kebersihan mulut dan kualitas hidup terkait kesehatan rongga mulut dengan DM.
Berdasarkan latar belakang ini maka penulis terdorong untuk mengevaluasi perbedaan indeks kebersihan mulut dan kualitas hidup terkait kesehatan rongga mulut pada pasien DMT2 dan yang non DM.

\section{METODE PENELITIAN}

Penelitian ini dilaksanakan di Instalasi Rawat Jalan Penyakit Dalam Rumah Sakit Nasional Diponegoro dengan jumlah sampel sebanyak 42 pasien. Jenis penelitian ini ialah analitik observasional dengan desain potong lintang. Kriteria inklusi penelitian yaitu: pasien wanita dan pria, usia 18-60 tahun, memiliki rekam medis kadar glukosa darah $<180 \mathrm{mg} / \mathrm{dl}$ (khusus untuk pasien DMT2), masih memiliki gigi yang dibutuhkan untuk pengukuran indeks kebersihan mulut dan kualitas hidup, tidak sedang menjalani atau memiliki riwayat terapi radiasi, dan tidak merokok maupun mengonsumsi alkohol. Kriteria eksklusi penelitian ialah pasien yang memakai gigi tiruan, memiliki penyakit keganasan, trismus, atau penyakit sistemik seperti kardiovaskular (hipertensi, jantung iskemik, gagal jantung kongenital, infeksi endokarditis), kelainan endokrin (kelainan kelenjar tiroid dan parotid serta kekurangan adrenalin), dan penyakit infeksi (hepatitis, tuberkulosis, HIV, dan AIDS).

Setelah menerima penjelasan mengenai penelitian ini dan menandatangani informed consent, subyek penelitian diminta mengisi kuesioner kualitas hidup terkait kesehatan rongga mulut (oral health impact profile-14/ OHIP-14) dan menjalani pemeriksaan kebersihan mulut dengan perhitungan oral hygiene index simplified (OHI-S) yakni memeriksa gigi 16, 11, 26, 36, 31, 46 dengan kaca mulut dan sonde half-moon untuk melihat adanya debris dan kalkulus sesuai skor yang ada. Nilai rerata skor indeks OHIS dan OHIP-14 kemudian dibandingkan antara kelompok pasien dengan DMT2 dan non DM.

Seluruh data yang dikumpulkan dilakukan editing, coding, entry, dan cleaning kemudian data hasil penelitian ini disajikan dalam bentuk rerata dan standar deviasinya. Data yang diperoleh kemudian diproses menggunakan SPSS (IBM SPSS Statistic 21) dan diuji normalitasnya menggunakan 
uji Shapiro-Wilk dan uji homogenitas menggunakan uji Levene. Perbandingan data dibuat dengan menggunakan uji $\mathrm{T}$ tidak berpasangan bila data terdistribusi normal sedangkan bila data terdistribusi tidak normal, perbandingan data menggunakan uji Mann-Whitney. Nilai $\mathrm{p}<0,05$ digunakan untuk menyatakan adanya perbedaan yang bermakna secara statistik.

\section{HASIL PENELITIAN}

Analisis deskriptif dilakukan untuk mengetahui gambaran umum data sampel penelitian. Data yang disajikan pada Tabel 1 meliputi jenis kelamin, usia, serta skor OHIS dan OHIP-14 dari subyek. Data jenis kelamin disajikan dalam bentuk frekuensi dan persentase. Data usia dan OHIS memiliki nilai $\mathrm{p}>0,05$ yang me-nunjukkan distribusi data normal; data OHIP-14 memiliki nilai $\mathrm{p}<0,05$ yang menunjukkan distribusi data yang tidak normal, sedangkan data jenis kelamin tidak dapat diuji normalitasnya karena merupakan jenis data nominal.

Analisis inferensial digunakan untuk membuktikan hipotesis. Analisis uji normalitas dengan uji Saphiro-Wilk dilakukan pertama kali untuk melihat distribusi data lalu uji homogenitas Levene dilakukan untuk melihat homogenitas data. Semua uji homogenitas data menunjukkan hasil homogen dan hasil uji normalitas menunjukkan bahwa distribusi data normal $(p>0,05)$, kecuali untuk OHIP-14. Oleh karena itu, perbedaan nilai rerata indeks OHIS dianalisis menggunakan uji $\mathrm{T}$ tidak berpasangan sedangkan perbedaan nilai rerata indeks OHIS dianalisis menggunakan uji Mann Whitney. Kedua pengujian tersebut menunjukkan nilai $\mathrm{p}<0,05$ yang menyatakan bahwa terdapat perbedaan bermakna dari indeks OHIS dan OHIP-14 pada kelompok pasien DMT2 dibandingkan kelompok pasien non DM.

\section{BAHASAN}

Hasil penelitian ini menunjukkan adanya perbedaan bermakna dari OHIS antara pasien DMT2 dibandingkan pasien non DM (3,17 vs $1,43, p<0,001)$. Pasien DMT2 memiliki nilai rerata OHIS yang lebih buruk daripada pasien non DM. Hasil penelitian ini didukung oleh temuan penelitian Sharma et $\mathrm{al}^{12}$ yang menunjukkan perbedaan bermakna dari OHIS antara pasien dengan DMT2 dengan kontrol tanpa DM, dan Barrientos et $\mathrm{al}^{13}$ yang menyatakan bahwa sebagian besar penyandang DMT2 memiliki kebersihan mulut yang buruk.

Tabel 1. Karakteristik umum subjek penelitian

\begin{tabular}{lccc}
\hline \multicolumn{1}{c}{ Variabel } & \multicolumn{2}{c}{ Kelompok } & p \\
& DMT2 & Non DM & $0,677^{*}$ \\
\hline Usia & $49,86 \pm 7,49$ & $45,67 \pm 13,28$ & - \\
$\quad$ Penis kelamin & $13(61,9 \%)$ & $14(33,3 \%)$ & \\
Laki-laki & $8(38,1 \%)$ & $7(66,7 \%)$ & $0,376^{*}$ \\
OHIS & $3,17 \pm 1,16$ & $1,43 \pm 0,49$ & $0,010^{*}$ \\
OHIP-14 & $7,14 \pm 3,48$ & $2,24 \pm 0,81$ & \\
\hline
\end{tabular}

Keterangan: *uji Shapiro-Wilk

Tabel 2. Perbedaan OHIS antara pasien DMT2 dan non DM

\begin{tabular}{lcc}
\hline Kelompok & OHIS & p \\
\hline DMT2 & $3,18 \pm 1,17$ & $<0,001^{\S}$ \\
Non DM & $1,44 \pm 0,49$ & \\
\hline
\end{tabular}

Keterangan: ${ }^{\S}$ Uji T tidak berpasangan
Tabel 3. Perbedaan OHIP-14 antara pasien DMT2 dan non DM

\begin{tabular}{lcc}
\hline Kelompok & OHIP 14 & p \\
\hline DMT2 & $7,14 \pm 3,48$ & $<0,001^{\ddagger}$ \\
Non DM & $2,24 \pm 0,83$ & \\
\hline
\end{tabular}

Keterangan: Uji Mann-Whitney 
Perbedaan indeks kebersihan mulut tersebut dapat diakibatkan oleh meningkatknya risiko kebersihan mulut yang lebih buruk pada pasien dengan DM. ${ }^{14}$ Terdapat beberapa mekanisme yang berperan dalam hal meningkatnya risiko untuk kebersihan mulut yang lebih buruk pada pasien dengan DMT2. Peningkatan kadar gula dalam cairan krevikular gingiva dan saliva dapat menjadi stimulus untuk peningkatan pertumbuhan koloni jamur dan bakteri seperti Mutans streptococci dan lactobacilli dalam rongga mulut yang selanjutnya meningkatkan risiko pasien DM untuk mengalami karies. Selain itu komplikasi mikrovaskular dari DM berupa neuropati perifer dapat menyebabkan disfungsi saliva yang mengakibatkan xerostomia yaitu salah satu faktor risiko pembentukan plak di gigi. ${ }^{4}$

Hasil yang berbeda dengan penelitian ini dilaporkan oleh Carnerio et $\mathrm{al}^{15}$ yang tidak mendapatkan perbedaan bermakna dari OHIS pada pasien DM dibandingkan subjek sehat non DM. Hal ini dapat disebabkan adanya faktor lain yang memengaruhi kebersihan mulut seperti merokok, kebiasaan maupun cara menyikat gigi, pendidikan, dan status sosioekonomi. Alasan tersebut didukung oleh temuan penelitian Sharma et $\mathrm{al}^{12}$ yaitu saat analisis perbandingan OHIS antara pasien DMT2 dan non DM dibatasi pada kelompok pasien dengan tingkat sosioekonomi menengah keatas dan kebiasaan merokok dengan hasil tidak terdapat perbedaan bermakna dari OHIS antara pasien DMT2 dan kontrol tanpa DM.

Penelitian ini menunjukkan adanya perbedaan bermakna dari OHIP-14 antara pasien DMT2 dibandingkan pasien non DM (7,14 vs 2,24, p<0,001), yaitu pasien DMT2 menunjukkan nilai rerata OHIP-14 yang lebih buruk daripada pasien non DM. Hasil penelitian ini sejalan dengan penelitian Pinho et al ${ }^{16}$ yang mendapatkan perbedaan bermakna dari OHIP-14 pasien DMT2 dan kontrol tanpa penyakit. Perbedaan indeks kualitas hidup terkait kesehatan rongga mulut antara pasien DMT2 dan pasien non DM dapat dikaitkan dengan meningkatnya risiko untuk berbagai masalah kesehatan rongga mulut pada pasien dengan DM seperti xerostomia, peningkatan akumulasi plak dan kalkulus, kandidasis, periodontitis, abses periapikal, dan sindrom mulut terbakar. Masalah-masalah kesehatan rongga mulut tersebut dapat mengakibatkan kesulitan dalam menelan dan mengunyah, napas yang bau, gigi ompong (edentulous), rasa tidak percaya diri, nyeri, peningkatan risiko penyakit sistemik yang terkait infeksi/ penyakit mulut dan gigi, serta berbagai gejala lainnya yang kemudian dapat memperburuk kualitas hidup pasien. ${ }^{17}$ Temuan yang berbeda didapatkan oleh Irani et al $^{18}$ yang tidak menemukan perbedaan bermakna dari rerata skor OHIP-49 antara pasien DMT2 dengan pasien non DM. Perbedaan dengan temuan pada penelitian tersebut mungkin dikarenakan perbedaan kuesioner (OHIP49) dan perbedaan tempat perekrutan responden penelitian, dimana pada penelitian tersebut responden dengan DMT2 direkrut dari klinik diabetes sementara kontrol non DM direkrut dari pasien yang datang ke rumah sakit gigi dan mulut.

Pada penelitian ini nilai rerata OHIP-14 pasien DM T2 masih termasuk kategori baik meskipun nilai rerata OHIP-14 lebih buruk daripada pasien non DM. Terdapat beberapa argumen yang mungkin dapat menjelaskan temuan ini. Pertama, meskipun pasien DM memiliki kesehatan mulut yang buruk yang selanjutnya dapat mengakibatkan berbagai keluhan, keluhan-keluhan tersebut bisa saja tidak dirasakan sangat mengganggu oleh pasien sehingga tidak terlalu banyak memengaruhi kualitas hidup pasien. ${ }^{17}$ Kedua, DM terkait dengan berbagai komplikasi lainnya selain penyakit gigi dan mulut yang keberadaannya juga dapat mengganggu kualitas hidup dan menyebabkan pasien menganggap remeh masalah kesehatan rongga mulut yang dialaminya. ${ }^{19}$

Keterbatasan penelitian ini, ialah pertama, pada penelitian ini terdapat beberapa faktor risiko dari kebersihan dan kesehatan rongga mulut seperti tingkat sosioekonomi, tingkat pendidikan, frekuensi menyikat gigi, membersihkan sela-sela gigi, dan frekuensi check-up rutin ke dokter gigi yang tidak diikutsertakan maupun dieksklusi dari penelitian ini sehingga dapat merancukan 
hasil temuan dari kebersihan dan kesehatan rongga mulut pada penelitian ini. Kedua, penelitian ini menggunakan desain potong lintang sehingga tidak luput dari keterbatasan yang diakibatkan oleh desain penelitian tersebut.

\section{SIMPULAN}

Terdapat perbedaan bermakna dari indeks kebersihan mulut dan kualitas hidup terkait kesehatan rongga mulut antara pasien DMT2 dengan non DM yang menunjukkan bahwa pasien dengan DMT2 memiliki kedua nilai yang lebih buruk dibandingkan dengan pasien non DM.

Diperlukan penelitian lanjut dengan lebih memperhatikan faktor lain yang memengaruhi kebersihan dan kesehatan rongga mulut yang menggunakan desain penelitian lebih tinggi seperti kohort prospektif.

\section{Konflik Kepentingan}

Penulis menyatakan tidak terdapat konflik kepentingan dalam studi ini

\section{DAFTAR PUSTAKA}

1. Barnett A. Oxford Diabetes Library: Type 2 Diabetes (2nd edition). UK: Oxford University Press, 2012.

2. International Diabetes Federation. [accessed 2018 Sep 15]. Available from: https: //www.idf.org/our-network/regionsmembers/western-pacific/members/ 104-indonesia.html.

3. Laporan Hasil Riset Kesehatan Masyarakat. Jakarta: Badan Penelitian dan Pengem bangan Kesehatan Kementerian Kese hatan Republik Indonesia, 2013.

4. Leite RS, Marlow NM, Fernandes JK, Herma yer K. Oral health and type 2 diabetes. Am J Med Sci. 2013;345(4):271-3.

5. Bajaj S, Prasad S, Gupta A, Singh VB. Oral manifestation in type 2 diabetes and related complications. Indian J Endocrinol Metab. 2012;16(5):777-9.

6. World Health Organization. 2016. Oral Health. [accessed 2019 Feb 21]. Available from: http://www.who.int/topics/oral_health/e $\mathrm{n} /$.

7. Mohsin SF, Fawwad A, Mustafa N, Shoaib A, Basit A. Impact of type 2 diabetes mellitus on oral health related quality of life among adults in Karachi, Pakistan: a cross-sectional study. British J Adv Med Med Res. 2017;20(1):1-7.

8. Poudel P, Griffiths R, Wong VW, Arora A, Flack JR, Khoo CL, et al. Oral health knowledge, attitudes and care practices of people with diabetes: a systematic review. BMC Public Health. 2018; 18(1):577.

9. Radhika T, Ranganathan K. Periodontal health in tye 2 diabetics. Journal of Dr. NTR University of Health Science. 2014; 3(5):37-42.

10. Sadeghi R, Taleghani F, Farhadi S. Oral health related quality of life in diabetic patients. J Dent Res Dent Clin Dent Prospect 2014; 8(4):230-234.

11. Trikkalinou A, Papazafiropoulou A, Melidonis A. Type 2 diabetes and quality of life.World J Diabetes. 2017;8(4):120-9.

12. Sharma R, Raj SS, Vino, K, Reddy YG, Desai $\mathrm{V}$, Bailoor D. Comparison of oral health indicators in type 2 diabetes mellitus patients and controls. J Indian Acad Oral Med Radiol. 2011;23(3):168.

13. Barrientos NA, Acosta MEH, Espinoza GA. Periodontal health conditions in patients with diabetes in a family medicine unit. Int J Fam Commun Med. 2019;3(3): 124-6. DOI: $10.15406 /$ ijfcm.2019.03. 00143

14. Mohamed HG, Idris SB, Ahmed MF, Bøe OE, Mustafa K, Ibrahim SO, et al. Association between oral health status and type 2 diabetes mellitus among Sudanese adults: a matched case-control study. PloS one. 2013;8(12)..

15. Carneiro VL, Fraiz FC, Ferreira FDM, Pintarelli TP, Oliveira ACB, Boguszewski MCDS. The influence of glycemic control on the oral health of children and adolescents with diabetes mellitus type 1. Arch Endocrinol Metab. 2015;59(6): 535-40.

16. Pinho RCM, de Melo Dias RSA, Bandeira F, da Silva Barbosa AC, Júnior ADFC, Cimões R. Impact of chronic periodontitis on the quality of life of individuals with and without diabetes. Health Science Journal. 2018;12(2):1-11.

17. Berutu MS, Dharmautama M. Kualitas hidup manula yang menggunakan gigi tiruan lengkap berdasarkan OHIP -14 di Kota Makassar (Quality of life of elderly using complete denture based on OHIP- 
14 in Makassar). Journal of Dentomaxillofacial Science. 2018;14(1):55.

18. Irani FC, Wassall RR, Preshaw PM. Impact of periodontal status on oral health-related quality of life in patients with and without type 2 diabetes. J Dent. 2015;
43(5):506-11.

19. de Sousa RV, Pinho RCM, Vajgel BDCF, de Paiva SM, Cimões R. Evaluation of oral health-related quality of life in individuals with type 2 diabetes mellitus. Braz J Oral Sci. 2019;18:1-16. 